\section{ARTICLE}

\title{
From taking to using medication: recovery-focused prescribing and medicines management ${ }^{\dagger}$
}

\author{
Elina Baker, Jason Fee, Louise Bovingdon, Tina Campbell, Elaine Hewis, \\ Danny Lewis, Lesley Mahoney \& Glenn Roberts
}

\section{Elina Baker is a clinical}

psychologist working at the Devon Partnership NHS Trust rehabilitation service in Exeter, UK. She has previously worked in secure and forensic services and has an interest in user involvement and recoverybased practice in in-patient setting Jason Fee is a consultant forensic psychiatrist working at the Butler Clinic at the Devon Partnership Trust forensic mental health service in

Dawlish, UK. Louise Bovingdon is a voluntary research assistant with the Devon Partnership NHS Trust Department of Clinical Psychology in Exeter. Tina Campbell is a pharmacist and Associate Director of Medicines Management for the Devon Partnership NHS Trust Elaine Hewis is a consultant trainer and lecturer in mental health and has lived experience of using medication for mental health reasons. Danny Lewis provides care and support to a family member who takes medication for mental health reasons. Lesley Mahoney is a staff nurse and medicines management link practitioner at the Russell Clinic at the Devon Partnership NHS Trust in-patient rehabilitation ward in Exeter. Glen Roberts is a consultant psychiatris working at the Devon Partnership NHS Trust rehabilitation service in Exeter. He leads on recovery for the Royal College of Psychiatrists and has written a number of articles on implementing recovery-based practice.

Correspondence Elina Baker Russell Clinic, Wonford House Hospital, Dryden Road, Exeter EX2 5AF, UK. Email: elina.baker@nhs.ne

${ }^{\dagger}$ For a commentary on this article see pp. 11-13, this issue.

\section{SUMMARY}

Mental health services are increasingly supporting recovery-oriented practice as a basis for service delivery. There is considerable overlap between the values and approaches associated with recovery-based practice and those already endorsed as good psychiatric practice. However, these agreed principles may not be consistently applied and further steps may be needed if the reorientation of the relationship between psychiatrists and people using psychiatric services is to fully reflect recovery principles. This article describes ways in which psychiatric practice could develop, including conceptualising medication as one of many possible recovery tools that a person can actively use to support their well-being, and a range of practices available to professionals to support people in taking up an active stance in relation to medication. It also identifies recovery-supportive practices for when someone is unable to fully participate in decision-making, owing to crisis, loss of capacity or concerns about safety.
\end{abstract}

\section{DECLARATION OF INTEREST}

None.

There has been a growing international endorsement of recovery principles as a foundation for mental health practice and services (Slade 2009). This is supported by a broad consensus, including the Royal College of Psychiatrists (Future Vision Coalition 2009), consolidated in government policy (HM Government 2011) and elaborated in authoritative guidance (Shepherd 2010). The College included the development of recoveryoriented practice in its Fair Deal campaign (Fitch 2008), and a position statement by consultant psychiatrists recommends that recovery principles should be incorporated into psychiatric practice across the whole spectrum of specialties (South London and Maudsley NHS Foundation Trust 2010).
Recovery is not a model. Rather, it reflects a set of guiding values. The most widely cited definition of recovery is:

'Recovery is a deeply personal, unique process of changing one's attitudes, values, feelings and goals, skills and/or roles. It is a way of living a satisfying, hopeful and contributing life even with the limitations caused by illness. Recovery involves the development of new meaning and purpose in one's life as one grows beyond the catastrophic effects of mental illness.' (Anthony 1993)

This definition describes the concept of 'personal recovery' (moving forwards in life), as distinct from 'clinical recovery' (getting better from symptoms or problems), which has traditionally been the focus of mental health services (Slade 2009).

\section{The recovery approach in practice}

Broad political, service and professional commitments to recovery leave many details to be worked out in terms of what application of a recovery approach means in practice with respect to specific care groups or settings. It has been suggested that a key challenge to organisations and practitioners is in supporting a shift in the nature of day-to-day interactions and the quality of experience for people who use services. This has been characterised as a shift from a core emphasis on treatment and adherence to one that is about enabling people to successfully manage their own difficulties through supporting self-management and self-directed care (Shepherd 2010).

\section{Existing frameworks}

Psychiatrists have always practised within a number of legal, ethical and good practice frameworks that require them to work collaboratively: the Mental Capacity Act 2005 and the guiding principles of the Mental Health Act 1983 Code of Practice (Department of Health 2008) stipulate that people taking decisions under these Acts must respect diversity and give patients the opportunity to be involved. 
These principles are further enshrined by professional bodies. For example, the General Medical Council's Good Medical Practice (2009) emphasises 'working in partnership with patients', and the Royal College of Psychiatrist's competency-based curriculum (2010) requires trainee psychiatrists to demonstrate 'an understanding of the need for involving patients in decisions, offering choices [and] respecting patients' views' (p. 44). The terms and conditions of the National Health Service (NHS) consultant contract specify involving patients in decisionmaking about their treatment as an associated duty and responsibility. The National Institute for Health and Clinical Excellence (NICE) guidance on medicines adherence (2009a) recommends a number of interventions for increasing people's involvement in decision-making about medication. These standards are clearly also at the heart of recovery-based practice.

\section{Putting principles into practice}

One of the frequently raised objections to adopting recovery as a basis for practice is that it does not represent the fundamental shift in approach that it claims, but that it is a restatement of core principles and values already agreed as foundational for medical practice, and that in effect "we are doing it already' (Davidson 2006; South London and Maudsley NHS Foundation Trust 2010). To a significant extent this is true. However, there is evidence to suggest that these commitments to the principles of collaborative and personcentred approaches have not always translated into practice (Seale 2006; Marshall 2011). There are likely to be important and complex reasons for this gap between values and practice and explicitly engaging with recovery ideas may help to identify ways in which practice could develop to address this. Further, the adoption of recoverybased practice is accompanied by progressive policy that encourages working out in detail the implications of guiding values and developing auditable strategies for implementation (Shepherd 2010; HM Government 2011), such that the way in which values are put into practice is evidenced.

\section{Personal and self-determined perspectives}

We would also suggest that the recovery approach not only reiterates but builds on these guiding values. In seeking to support the development of personal meaning and achievement of individually determined goals, recovery approaches would represent a significant shift of emphasis and commitment for psychiatric practice, rebalancing traditional focus on diagnosis and treatment with prioritisation of personal and self-determined perspectives. A key component of this shift would be the value and status that is ascribed to different forms of knowledge. Traditional prescribing practice is underpinned by scientific theory and a corresponding evidence base, central to which is the randomised controlled trial, which is taken as the gold standard in compiling treatment guidelines. The recovery approach values the evidence of personal narrative and places greater emphasis on the experiences and preferences of the individual. It has consequently been described as reflecting values-based practice, which is complementary to but also contrasted with evidence-based practice (Slade 2009).

\section{The practitioner/service user relationship}

Recovery-based practice, therefore, requires a change in the nature of the relationship between professionals and people using services. This has been identified as one of the ten key challenges with which organisations and services need to engage to support recovery (Shepherd 2010), which may pivot around renegotiating issues of power, control and authority, as this journal has discussed before (Roberts 2007). This emphasis anticipates a transformation in relationships between practitioners and people who use services, such that both are considered experts, practitioners by virtue of their training and clinical experience and service users by virtue of their personal knowledge and lived experience (Deegan 2006). The role of the professional is thus transformed from authority to coach who offers knowledge to support an individual in pursuing their personal goals (this journal, Roberts 2004; Rethink 2011). It is important to emphasise that recovery-based practice does not, therefore, involve discarding scientific professional knowledge and evidence bases. Rather, these gain value in supporting outcomes when brought into a dialogue about how a person can actively participate in furthering their own recovery process (South London and Maudsley NHS Foundation Trust 2010).

In this article, we outline ways in which psychiatric practice could develop to reflect this shift, exploring how medication can best be understood to relate to the personal recovery process, describing practices that could support the use of medication as a self-management strategy and discussing how recovery-based practice could be maintained at times when people are unable to make choices or when their choices might compromise their own safety or the safety of others. 


\section{The role of medication in recovery: from 'taking' to 'using'}

Published personal narratives or 'recovery stories' and the results of research studies reflect a wideranging and highly individualised experience of psychiatric medication (Coleman 1999; Mead 2000; Lapsley 2002; May 2004; Deegan 2005; Read 2009; Rethink 2009; Cordle 2010; Baker 2011). Some people describe medication as essential to their recovery, often as a way of getting difficult symptoms under control and thus providing a foundation for building a meaningful life. Often there has been a process of finding the 'right' medication (one that is effective for them), which will have involved trial and error and negative experiences, as well as a process of coming to terms with the need to take medication for life to be manageable. Thus, accounts of positive and negative experiences of medication can coexist within the same story.

Concerns about medication are also often expressed, with some people feeling that the unpleasantness of the side-effects outweighs any benefits and could actually undermine recovery. There are accounts of people feeling disempowered and even traumatised by lack of information and choice about medication, including compulsory treatment. There are many accounts of how people have found other approaches to managing their difficulties to be beneficial, both alongside or instead of medication. These include psychosocial interventions and self-help strategies, described as 'wellness tools' (Copeland 2004), 'personal medicines' (Deegan 2005) or 'self-management' (Rethink 2003). However, many accounts describe these options as having limited availability or not being considered or offered with the same frequency as medication.

Personal recovery is a unique, individual process, so it is unsurprising that medication has played very different roles, and at different times, in the recovery journeys of different people. We suggest that it is not only the potential effectiveness of the medication itself but the nature of the relationship that people have with their medication that can be thought of as supportive or unsupportive of personal recovery. The traditional experience has been a passive process of taking medication, following the direction of an expert professional. Indeed, the term 'prescribing' has these connotations, with the Oxford English Dictionary definition outside of medical contexts being 'to state authoritatively that an action or procedure should be carried out'. A key component of recovery is taking up an active stance in relation to one's own difficulties. This would be better supported by a relationship with medication that is characterised by actively using it (Deegan 1996), by making informed choices about its effects and how these relate to desired outcomes. This has been described as 'using medication thoughtfully' (Lapsley 2002: p. 65). The role of medication in supporting personal recovery can, therefore, be reconceptualised not just as a treatment but as one tool among many that a person can choose to use to help them achieve their personal recovery goals (Deegan 1995; Mead 2000; Slade 2009). It is a tool that may gain in value and benefit if supported by the person's thought-out acceptance and commitment.

We recognise that, in some circumstances of risk and incapacity, people cannot fully participate in making choices about whether and how to use medication. While we believe these circumstances to be exceptional, ${ }^{\mathrm{a}}$ they are also the most problematic in terms of working out the detail of putting recovery principles into practice and we will discuss them in more detail later in this article.

\section{Supporting an active stance in relation to medication}

\section{Making shared decision-making a reality}

Shared decision-making, in which the expertise of both parties is recognised, has been identified as a desirable approach to prescribing practice by policy makers and healthcare professionals. There is evidence that is it effective (Marshall 2011) and that it supports recovery values (Deegan 2006). However, the accounts of people using mental health services, along with observations and surveys of psychiatric practice, all suggest that it is not fully implemented, with psychiatrists often using persuasion to improve adherence (Seale 2006, 2007; Ranz 2008; Baker 2011). This has also led to a tendency for mental health workers to withhold information about possible adverse effects of medication (Pollock 2004; Chaplin 2007, this journal). For psychiatrists working within evidence-based frameworks, this is likely to reflect a view, based on training and research, that taking medication is in people's best interests. This contrasts with a recovery-based approach, with its emphasis on personal experience, choice and responsibility, allowing 'the dignity of risk and the right to failure' (Deegan 2005) and the opportunity to learn from experience. For many psychiatrists, this will inevitably be a source of dilemmas and discomfort and, in addition to the possible strategies that we describe here, psychiatrists will need professional and organisational support that recognises that genuinely sharing decisions requires sharing of responsibility and risk. 


\section{Informing patients}

There are many possible sources of information that people can use to support their decisionmaking about medication. However, they are all subject to well-understood biases and limitations. The outcomes and availability of data from randomised controlled trials, which are the cornerstone of the prescribing evidence base, may be influenced by funding sources, such as pharmaceutical companies, and will also say little about the experience of individuals or the longerterm impact of medications (Moncrieff 2008; Read 2009; Slade 2009). Drawing on support from peers with their own experiences of mental health difficulties and referring people to the recovery stories of others has been identified as valuable for the personal recovery process (Slade 2009). However, personal accounts of medication usage will be representative only of one individual's experience and will be influenced by their personal values, priorities and lifestyle. Therefore, an important task in recovery-based prescribing would be to help people to be aware of both the range of sources and how to evaluate them. Some useful resources, reflecting a range of perspectives, are shown in Box 1.

\section{Alternative strategies}

Alongside supporting people to weigh the costs and benefits of medication options, a recoverybased approach would also incorporate raising awareness of alternative strategies that people have found useful in managing their difficulties. There is now substantial evidence for the benefits of supporting people in self-management across the whole of medicine, although clinicians may need help to develop the relevant attitudes and skills (Health Foundation 2011). This may be an area where psychiatrists currently feel less confident and less equipped (Ranz 2008). The College's competency-based curriculum for psychiatric training (Royal College of Psychiatrists 2010) explicitly requires trainees to be 'aware of strategies to enhance patient understanding and potential self-management' (p. 57), indicating that this is supported as a future direction for the profession. Deegan (2008a) describes how questions and information about 'personal medicines' can be included in psychiatric consultations. A wealth of evidence is available to demonstrate the impact of particular activities on well-being, which is summarised in the Ten Keys for Happier Living that underpin the current strategy from Action for Happiness (www.actionforhappiness.org). These could be used by psychiatrists as the basis of social prescribing (Care Services Improvement
Partnership 2009), where people are told how to link to a variety of activities that could improve their mental health, including arts, exercise and time in the natural environment, or to direct people towards techniques to improve their mood and management of emotions.

\section{Selecting the best tool for the individual}

Exploring information about medication and personal medicines may guide a decision but ultimately there will be a need to evaluate which tools are useful for a particular person. Within a recovery-based approach, decisions about using or changing medications, including different types or doses, can be treated as collaborative experiments (Deegan 2006). This involves agreeing on the aim of using or changing the medication, identifying ways of monitoring the effects and agreeing what action will be taken if the experiment is unsuccessful. A simple measuring scale or other self-monitoring tool might be used as a way of keeping track of experience over time, providing a basis for discussing the results of the experiment.

\section{B0X 1 Useful online sources of information about medication}

\section{Choice and medication website: www.} choiceandmedication.org.uk

Offers people information about medication for mental health to enable them to make informed decisions.

National Prescribing Centre patient decision aids (anxiety, insomnia, schizophrenia): www.npci.org.uk/ patient_decision_aids

The NPC has developed patient decision aids to help patients make difficult decisions about treatment when they need to weigh benefits against risks.

Mind information booklets: www.mind.org.uk/help/ medical_and_alternative_care

Provide free information about a range of treatments, including medication, psychological and complementary therapies.

Rethink website: www.rethink.org/living_with_mental_ illness/treatment_and_therapy/index.html

Provides information about a range of treatments and medication, including Only the Best (Rethink 2006), a guide to help people to find the best antipsychotic and mood stabiliser medication for them.

Coming Off Psychiatric Medication website: www. comingoff.com

Gives information about psychiatric medication and the withdrawal process, from people who have used and withdrawn from medication and clinicians who have supported this process. 
The person's informal support network might also be involved (Deegan 1995). In this way, decisions can be based on the evidence of research, experiences of clinicians and other people who have taken the medication, and a structured approach to collecting the evidence of personal experience.

\section{Balancing demands}

Fully engaging with shared decision-making is a demanding process for clinicians in requiring more time and practical resources but also in the degree of uncertainty for both the prescriber and the person taking medication. This may contribute to the disparity between aspirations for practice and the lived experience of people taking medication as described above. However, there is evidence that the way in which prescribing is carried out influences how effectively medicines are used and even the effectiveness of the medicines themselves (Britten 2010, this journal; Mintz 2011). Using the recovery stories of others can be a helpful strategy to inspire hope for people engaged in the personal recovery process and, in this spirit, we offer in Box 2 an example of a successful approach to prescribing based on recovery principles.

\section{Resolving conflicting perspectives}

Supporting personal meanings

Finding meaning and developing a personally satisfactory account of mental health difficulties

\section{B0X 2 Decision support centres}

Deegan et al (2008) describe an evaluation of a peer-run decision support centre, established to assist shared decisionmaking practice at an out-patient psychiatric medication clinic in the mid-west of the USA. People attending for medication appointments were given 30 minutes in the centre before meeting with their prescriber, where they received support from peers in using a computer program to:

- hear personal accounts of recovery;

- reflect on their 'personal medicines' (things they did to support their own wellness);

- rate their symptoms and functioning since their last visit;

- report how they had been using their medication;

- identify common concerns and goals for their meeting with the prescriber.

Their responses were then forwarded electronically to the prescriber and the report was reviewed in the consultation. Decision-making aids (such as a balance sheet of costs and benefits) were then used to make shared decisions about how the person would use their medication or other strategies they had identified. The centre also provided informal peer support and access to information about medication via the internet.

The evaluation comprised focus groups, which included medical practitioners working at the clinic and clients. Medical practitioners felt that they gained a more holistic understanding of their clients' needs and clients could communicate more effectively about their concerns so that they were able to be more actively involved in the prescribing process. Clients found that the personal accounts of recovery inspired hope. They also felt that using the computer program meant that their concerns were more likely to be heard and they found it useful to be able to track their progress. and distress is described as a key component of personal recovery (May 2004; Slade 2009). However, these accounts are often divergent from the biomedical and biopsychosocial models espoused by the majority of mental health workers. 'Lay understandings' have been identified as a factor in non-adherence to psychotropic medications, as highlighted in this journal (Britten 2010) and are often understood as reflecting a lack of insight (Slade 2009), which may then become a target for intervention in itself. Such individual clinical conflicts take place within the context of considerable controversy about the mode of action of psychiatric medication, whether it specifically treats an underlying brain disease or operates through a more generalised sedating or stimulant effect. These hypotheses relate to wider unresolved debates about the causes of mental distress or disorder and the relative role of biological, psychological and social factors (Breggin 1993; Read 2004; Moncrieff 2008).

To support personal recovery, practitioners may need to engage with people in a process of searching for meanings that are useful to them, rather than providing a particular framework for understanding their experience. This corresponds to the shift from 'expert' to 'coach' mentioned above. It would require the practitioner to attend to the person's existing ideas and beliefs about what has happened, before discussing with the person how there are multiple ways of making sense of, and therefore attempting to address, their problems and thinking with them about what they feel would be most useful to them (May 2004). Many people with psychosis value their experiences, or some aspect of them, and it is possible to support people to find ways of living with unusual experiences and beliefs that are less distressing or problematic for them and others (Romme 1993; Coleman 1999; Knight 2005). However, there are others who believe that experiences are best understood as an illness that needs to be treated (Allen 2006). A biomedical or biopsychosocial model should, therefore, be represented in this discussion, along with the use of medication as an associated strategy. Long-term perspectives illustrate how preferred models of understanding and choices of treatment shift over time and, because recovery is an ongoing process, it seems likely that support for people in the search for meaning will also need to be continuing and responsive to new experiences.

Although an individual may not favour a biomedical explanation of their difficulties or experiences, they may still find medication useful in achieving their recovery goals. Moncrieff 
(2008) argues that, despite uncertainty about how psychiatric drugs operate, the individual may still consider their effects desirable, for example in helping them feel calmer, less frightened or confused and improving sleep. Discussion of medication could, therefore, focus on its likely effects and whether the individual would find these helpful. Rather than viewing medication as a specifically biomedical treatment for a mental illness, framing it as an empirical strategy, with costs and benefits, that people can use to manage their mental states is supportive of the personal meanings necessary for recovery and may serve to resolve conflicting perspectives.

\section{Safety and compulsion}

The call from the recovery movement for increased responsibility for, and respect for the choices of, people using mental health services has led to concerns about potential negligence, described as 'leaving people to rot with their rights on' (Davidson 2006). At such times, it would be both irresponsible and unsupportive of longer-term personal recovery for mental health workers not to intervene, as this journal has reported (Roberts 2008). Under these circumstances, depending on whether someone is detained, practice is guided by either the Mental Capacity Act 2005 or the Mental Health Act 1983 Code of Practice (Department of Health 2008).

\section{The Wellness Recovery Action Plan}

Both people with lived experience and advocates of recovery-based practice acknowledge the need for others to intervene at times of crisis. The development of a 'crisis plan', outlining preferred supporters, interventions and criteria for activating and inactivating the plan, is a core component of a Wellness Recovery Action Plan, a widely used self-management tool (Copeland 2004). This approach can maintain the person's involvement and ensure that treatment decisions continue to be guided by their values and preferences (Deegan 2006). Helping people to prepare such documents at times when they are stable is therefore essential to a recovery approach. However, it is important to be honest with people about the limitations on the practitioner in respecting their choices (Noordsy 2000). Crisis plans can be made in the form of advance statements, as described in the Mental Capacity Act. However, with the exception of advance decisions (which are refusals of particular treatments), these can be overridden, and in general such statements are trumped by the amendments to the Mental Health Act made in 2007.

\section{Exploring strategies to maintain recovery}

Where it is not possible to abide by a person's previously expressed preferences (either in the absence of a plan or where it has proved insufficient), the Mental Health Act Code of Practice (Department of Health 2008) requires that psychiatrists engage fully with the person's wishes. Roberts and colleagues (2008) describe in this journal a number of strategies through which a recovery-based process can be maintained in relation to medication when someone is detained. These include exploring people's previous experiences of medication, the ways in which they are making sense of their difficulties and what other strategies they might find helpful, as well as offering people choice from a more limited range of options, such as choosing between possible medications and when, where and how they would like the medication administered. As many people with mental health difficulties are distressed by the idea of putting themselves or others at risk (Langan 2004), a collaborative approach to risk assessment and management, where the person is engaged in a process of identifying strategies to help them remain safe, is likely to be both effective and beneficial.

\section{Distinguishing 'me' from 'it'}

Mead $\&$ Hilton (2003) describe how a strategy of externalising problems derived from White's (1990) approach to narrative therapy can be effective as part of this process. This approach capitalises on the value in recovery of distinguishing 'me' from 'it' (Davidson 1992) by encouraging people to see the problem as a separate entity from themselves, to allow them to think about the influence the problem is having on their lives and how they might take action against it. The person supporting them can then unite with them in their struggle against the problem. Instead of focusing on controlling risky behaviours, this approach could enable a dialogue with the person about their preferred ways of behaving (which are likely to be less risky) and whether and how medication, alongside other strategies, could support them in resisting the influence of the problem.

\section{Post-crisis planning}

Personal recovery is conceptualised as a journey in which there will be inevitable setbacks, so times of crisis and compulsory treatment could usefully be recontextualised as learning experiences, rather than thought of as failures. The Wellness Recovery Action Plan concludes with 'post-crisis planning', which provides an opportunity, after 
a crisis has resolved, to reflect on how things could have been handled differently. As part of this process, it may be helpful for mental health workers to find a way to acknowledge the person's feelings about any actions that were taken against their wishes and to negotiate with them to develop or revise a crisis plan to prevent similar situations in future, as previously proposed in this journal (Copeland 2008). The National Institute for Health and Clinical Excellence (2009b) guideline on schizophrenia recommends that people should be given the opportunity to record their own account of rapid tranquillisation in their notes and this approach could be extended to other forms of compulsory treatment and people with other diagnoses.

\section{Enforced medication outside of crises}

There may be times outside of clear crisis situations where there is a perceived need to enforce medication as a strategy to manage future risk (Langan 2004). A full discussion of a recoverybased approach to risk management is beyond the scope of this article. However, such an approach, involving working collaboratively with the person using services, emphasising strengths and supporting choice and the development of self-management skills, has been identified as best practice (Department of Health 2007). Again, there has been only slow and partial implementation of this guidance, and 'changing the way we approach risk assessment and management' is identified as another of the key organisational challenges for implementing recovery (Shepherd 2010), which will be supported by an NHS Confederation guidance paper in due course (Boardman 2013).

\section{Conclusions}

It is apparent that recovery values reflect those already underpinning good psychiatric practice and overlap with commitments already made to future professional competencies. However, there is evidence to suggest that these are not consistently translated into practice and this may account for the experiences of people using services, the voices of whom have substantially contributed to the development of the recovery approach and the ambitions for system transformation that it embodies. We have attempted to describe how recovery values would require a fundamental reorientation in the relationship between psychiatrists and people using services, such that personal experiences and meanings take on equal value to scientific evidence and theory so that practice is explicitly driven by values such as inclusion, choice and empowerment.
Adopting recovery as a basis for practice would require psychiatrists to put people's goals and preferences in the foreground, offer their knowledge as relevant and help people to make informed choices about how to make sense of and manage their difficulties. We believe that adopting the practices described in this article would support a recovery-based approach to the use of medication.

Within the Devon Partnership NHS Trust, we have developed good practice guidance to for practitioners on implementing recovery principles in relation to prescribing and medicines management, which incorporates these and other strategies (Devon Partnership Trust Recovery and Independent Living Professional Group 2010). This was adopted by the College's Fair Deal campaign as an illustration of implementing recovery in practice. It has much in common with established good practice principles, but it also extends these to a degree that has been described as a 'paradigm shift' (Slade 2009), with the attendant challenge for practitioners to develop new ways of thinking about and relating to people experiencing mental health difficulties. There will need to be an ongoing process of working out what it means in practice for all mental health workers and, in particular, of continually engaging with the tension between promoting autonomy and professional responsibilities.

We offer our thoughts and locally developed guidance as a contribution to continuing development and debate. We also recognise that there is a need for further work focused on the implementation of these ideas and evaluation of whether they effectively support people in using medication successfully to support them in their personal recovery.

\section{References}

Allen C (2006) Misplaced Pride. Guardian, 27 September.

Anthony WA (1993) Recovery from mental illness: the guiding vision of the mental health system in the 1990s. Innovations and Research 2 : 17-24.

Baker E, Bovingdon L, Campbell T, et al (2011) How Can Medication Be Used in Support of Recovery? The Views and Experiences of People Taking Medication, Carers and Workers. Recovery Devon.

Boardman J, Roberts G (2013) Risk, Recovery and Safety. NHS Confederation/Centre for Mental Health (in press).

Breggin P (1993) Toxic Psychiatry. Fontana

Britten N, Riley R, Morgan M (2010) Resisting psychotropic medicines: a synthesis of qualitative studies of medicine-taking. Advances in Psychiatric Treatment 16: 207-18.

Care Services Improvement Partnership (2009) Social Prescribing for Mental Health - A Guide to Commissioning and Delivery. CSIP North West Development Centre.

Chaplin R, Lelliot P, Quirk A, et al (2007) Negotiating styles adopted by consultant psychiatrists when prescribing antipsychotics. Advances in Psychiatric Treatment 13: 43-50. 
Coleman R (1999) Recovery: An Alien Concept. Handsell Publishing.

Copeland M, Mead S (2004) Wellness Recovery Action Plan and Peer Support. Peach Press.

Copeland ME, Mead S (2008) Continuing the dialogue. Invited commentary on: Detained: what's my choice? Part 1. Advances in Psychiatric Treatment 14: 181-2.

Cordle H, Fradgely J, Carson J, et al (eds) (2010) Psychosis: Stories of Recovery and Hope. Quay Books.

Davidson L, Strauss J (1992) Sense of self in recovery from severe mental illness. British Journal of Medical Psychology 65: 131-45.

Davidson L, O'Connell M, Tondora J, et al (2006) The top ten concerns about recovery encountered in mental health system transformation. Psychiatric Services 57: 640-5.

Deegan P (1995) Principles of a Recovery Model Including Medications. National Empowerment Centre.

Deegan $P$ (1996) Recovery as a journey of the heart. Psychiatric Rehabilitation Journal 19: 91-7.

Deegan P (2005) The importance of personal medicine: a qualitative study of resilience in people with psychiatric disabilities. Scandinavian Journal of Public Health 33: 29-35.

Deegan P, Drake RE (2006) Shared decision making and medication management in the recovery process. Psychiatric Services 57: 1636-9.

Deegan P (2008a) The Personal Medicine ${ }^{T M}$ and Recovery Toolkit and Tips on How to Use it in Your Organization. PDA.

Deegan PE, Rapp C, Holter M, et al (2008b) A program to support shared decision making in an outpatient psychiatric medication clinic. Psychiatric Services 59: 603-5.

Department of Health (2007) Best Practice in Managing Risk: Principles and Evidence for Best Practice in the Assessment and Management of Risk to Self and Others in Mental Health Services. Department of Health.

Department of Health (2008) Code of Practice: Mental Health Act 1983. TSO (The Stationery Office)

Devon Partnership Trust Recovery and Independent Living Professional Experts Group (2010) Recovery Orientated Prescribing and Medicines Management (Advisory Paper 8). Recovery Devon.

Future Vision Coalition (2009) A Future Vision for Mental Health. Future Vision Coalition (http://www.newvisionformentalhealth.org.uk/A future_vision_for_mental_health.pdf).

General Medical Council (2009) Good Medical Practice. GMC

Healthcare Commission (2007) Talking About Medicines: The Management of Medicines in Trusts Providing Mental Health Services. Healthcare Commission.

Health Foundation (2011) Evidence: Helping People Help Themselves. The Evidence Centre.

HM Government (2011) No Health Without Mental Health: A CrossGovernment Mental Health Outcomes Strategy for People of All Ages. Department of Health

Knight T (2005) You'd better believe it: Accepting and working within the client's own reality. Clinical Psychology Forum 155: 38-42.

Langan J, Lindow V (2004) Living with Risk: Mental Health Service User Involvement in Risk Assessment and Management. Joseph Rowntree Foundation.

Lapsley H, Nikora LW, Black R (2002) 'Kia Mauri Tau!': Narratives of Recovery from Disabling Mental Health Problems. Mental Health Commission.

Marshall M, Bibby $J$ (2011) Supporting patients to make the best decisions. BMJ 342: d2117.

May R (2004) Making sense of psychotic experiences and working towards recovery. In Psychological Interventions in Early Psychosis (eds J Gleeson, P McGorry): 245-60. Wiley.

Mead S, Copeland ME (2000) What recovery means to us: consumers' perspectives. Community Mental Health Journal 36: 315-28.

Mead S, Hilton D (2003) Crisis and connection. Psychiatric Rehabilitation Journal 27: 87-94.
Mintz D (2011) Psychodynamic psychopharmacology. Psychiatric Times, 9 September.

Moncrieff J (2008) The Myth of the Chemical Cure. Palgrave Macmillan.

National Institute for Health and Clinical Excellence (2009a) Medicines Adherence: Involving Patients in Decisions about Prescribed Medicines and Supporting Adherence. NICE.

National Institute for Health and Clinical Excellence (2009b) Core Interventions in the Treatment and Management of Schizophrenia in Primary and Secondary Care (Update). NICE.

NHS Information Centre for Health and Social Care (2011) Mental Health Bulletin: Fourth Report from Mental Health Minimum Datasheet (MHMDS) Annual Returns, 2010. HSCIC (http://www.ic.nhs.uk/pubs/ mhbmhmds0910).

Noordsy DL, Torrey WC, Mead S, et al (2000) Recovery oriented psychopharmacology: redefining the goals of anti-psychotic treatment. Journal of Clinical Psychiatry 61 (suppl 3): 22-9.

Pollock K, Grime J, Baker E, et al (2004) Meeting the information needs of psychiatric inpatients: staff and patient perspectives. Journal of Mental Health 13: 389-401.

Ranz JM, Mancini AD (2008) Psychiatrists' reports of their own recoveryoriented practices. Psychiatric Services 59: 100-4.

Read J, Mosher L, Bentall RP (2004) 'Schizophrenia' is not an illness. In Models of Madness: Psychological, Social and Biological Approaches to Schizophrenia (eds J Read, L Mosher, RP Bentall): pp. 3-7. Routledge.

Read J (2009) Psychiatric Drugs: Key Issues and Service User Perspectives. Palgrave Macmillan.

Rethink (2003) The Experiences and Views of Self-Management of People with a Diagnosis of Schizophrenia. Rethink.

Rethink (2006) Only the Best: Information about Antipsychotic and Mood Stabiliser Medication. Rethink (http://www.rethink.org/document. rm? id=1116).

Rethink (2009) Getting Back into the World: Reflections on Lived Experiences of Recovery. Rethink.

Rethink (2011) REFOCUS: Promoting Recovery in Community Mental Health Services. Rethink.

Roberts G. Wolfson P (2004) The rediscovery of recovery: open to all. Advances in Psychiatric Treatment 10: 37-48.

Roberts G, Hollins S (2007) Recovery: our common purpose? Advances in Psychiatric Treatment 13: 397-9.

Roberts G, Dorkins E, Wooldridge J, et al (2008) Detained: what's my choice? Part 1: Discussion. Advances in Psychiatric Treatment 14: 172-80. Romme M, Escher S (1993) Accepting Voices. Mind Publications.

Fitch C, Daw R, Balmer N, et al (2008) Fair Deal for Mental Health: Our Manifesto for a 3 Year Campaign Dedicated to Tackling Inequality in Mental Healthcare. Royal College of Psychiatrists.

Royal College of Psychiatrists (2010) A Competency Based Curriculum for Specialist Core Training in Psychiatry. Royal College of Psychiatrists.

Seale C, Chaplin R, Lelliot P, et al (2006) Sharing decisions in consultations involving anti-psychotic medications: A qualitative study of psychiatrists' experiences. Social Science and Medicine 62: 2861-73.

Seale C, Chaplin R, Lelliot P, et al (2007) Anti-psychotic medication, sedation and mental clouding: an observational study of psychiatric consultations. Social Science and Medicine 65: 698-711.

Shepherd G, Boardman J, Burns M (2010) Implementing Recovery: A Methodology for Organisational Change. Sainsbury Centre for Mental Health.

Slade M (2009) Personal Recovery and Mental IIIness: A Guide for Mental Health Professionals. Cambridge University Press.

South London and Maudsley NHS Foundation Trust, South West London and St George's Mental Health NHS Trust (2010) Recovery Is For All: Hope, Agency and Opportunity in Psychiatry. A Position Statement by Consultant Psychiatrists. SLAM/SWLSTG.

White M, Epston D (1990) Narrative Means to Therapeutic Ends. WW Norton.

\section{MCO answers \\ $1 d$ d \\ $4 b \quad 5 d$}




\section{MCOs}

Select the single best option for each question stem

1 Services that focus on personal recovery:

a are aimed at reducing symptoms

b ensure that people follow their treatment plans

c offer standardised interventions

d support people in building a meaningful and valued life through personalised strategies

e do not provide medication.

2 Medication supports personal recovery:

a by effectively treating symptoms

b by effectively preventing relapse

c by providing a tool that people can use to achieve personal recovery goals

$d$ because it is the only available option for many people

e only when the person agrees with their diagnosis.
3 People can be supported to take an active stance towards their medication by:

a a process of shared decision-making in which they make informed choices

b being given clear instructions on how to take their medication correctly

c being told that medication is essential to manage their symptoms

$\mathrm{d}$ being given reassurance that professionals know which medication they need

e having their medication changed if they continue to experience symptoms.

4 In a recovery-focused conversation about medication:

a the person is encouraged to accept their diagnosis

b there is a discussion about the likely effects of the medication and whether these will help the person reach their recovery goals c the person is not given much information about the medication, as this can reduce adherence

$d$ the person is told that they will need medication for the rest of their life

e the person is encouraged not to ask others about their experience of medication.

5 When a person has a crisis plan for use at times when they cannot safely make choices for themselves:

a the crisis plan should be respected at all times

b the crisis plan should be ignored if the person is detained under the Mental Health Act

c the crisis plan should be ignored if the person's relatives disagree with it

$d$ the crisis plan may provide a useful guide to the person's wishes but can be overridden by the Mental Health Act

e if the plan could not be followed in a crisis, the person should be discouraged from using a crisis plan in future. 